\section{A EDUCAÇÃO FÍSICA EM UMA ESCOLA MILITAR: DE TURMAS SEPARADAS POR SEXO E POR ALTURA A TURMAS MISTAS}

\author{
PHYSICAL EDUCATION IN A MILITARY SCHOOL: FROM CLASSES \\ SEGREGATED BY SEX AND HEIGHT TO MIXED CLASSES
}

\author{
LA EDUCACIÓN FÍSICA EN UNA ESCUELA MILITAR: DE CLASES \\ SEPARADAS POR SEXO Y POR ALTURA A CLASES MIXTAS
}

\author{
Lara Felix Jacoby*, Silvana Vilodre Goellner*
}

\begin{abstract}
Palavras chave: Educação Física. Gênero.

Ensino

Fundamental e Médio.

Educação.

Resumo: O presente estudo tem como objetivo descrever o processo de transição de turmas separadas (por sexo e altura) para turmas mistas nas aulas de Educação Física do sexto e sétimo anos do Ensino Fundamental do Colégio Militar de Porto Alegre. Sua fundamentação teórico-metodológica está ancorada nos Estudos de Gênero e na História Oral. Foram realizadas quatro entrevistas com docentes da instituição. Os dados advindos das entrevistas foram cotejados com documentos do Sistema Colégio Militar do Brasil e outros referentes às questões de gênero e de coeducação na Educação Física. Considerando a alteração dos critérios de organização das turmas, realizada no início de 2018, os docentes mencionam o quanto esta nova configuração demandou alterações na sua conduta, visto estarem habituados a trabalhar o conteúdo esportivo levando em conta a diferença que identificam entre habilidades e performances de alunos e alunas.
\end{abstract}

Keywords:

Physical

Education.

Gender.

Primary and

Secondary

Education.

Education.

Palabras clave: Educación Física. Género.

Educación Primaria y secondaria. Educación.

Abstract: This study describes the transition from Physical Education classes segregated - by sex and height - to mixed classes in sixth and seventh Elementary School grades in Porto Alegre's Military School. Its theoretical framework is Gender Studies and Oral History: four interviews were conducted with teachers of that institution. Data collected in the interviews were combined with documents from Brazil's Military School System and others related to gender issues and coeducation in Physical Education. Considering the change in class organization criteria carried out at the beginning of 2018 , the teachers mentioned the many changes this new configuration demanded in their conduct, since they were used to working with sports content taking into account the difference between skills and performances of male and female students.

Resumen: Resumen: El presente estudio tiene por objetivo describir el proceso de transición de clases separadas (por sexo y por altura) a clases mixtas en la Educación Física de sexto y séptimo años de la enseñanza fundamental en la Escuela Militar de Porto Alegre. Sus fundamentos teóricos y metodológicos están anclados en los Estudios de Género y en la Historia Oral: se realizaron cuatro entrevistas con docentes de la institución. Los datos obtenidos por las entrevistas se contrastaron con documentos del Sistema Colegio Militar de Brasil y con otros referentes a cuestiones de género y de coeducación en Educación Física. Considerando la alteración de los criterios de organización de las clases, realizada a inicios del 2018, los docentes mencionan hasta qué punto esta nueva configuración demandó alteraciones en su conducta, dado que estaban habituados a trabajar el contenido deportivo teniendo en cuenta la diferencia que identifican entre habilidades y performances de alumnos y alumnas.
*Universidade Federal do Rio Grande do Sul. Porto Alegre, RS, Brasil.

E-mail:

larafel@gmail.com; vilodre@gmail.com

Recebido em: 08-07-2019 Aprovado em: 23-03-2020 Publicado em: 28-04-2020 (c) (i) (8) Licence 


\section{INTRODUÇÃO}

O Colégio Militar de Porto Alegre (CMPA) é uma instituição de ensino que faz parte do Sistema Colégio Militar do Brasil (SCMB) composto por treze colégios militares (CMs) que atendem do sexto ano do Ensino Fundamental (EF) ao terceiro ano do Ensino Médio (EM). O ingresso dos/as alunos/as pode acontecer por meio de concurso ou por reserva de vagas a filhos/as de militares, que são maioria.

Os CMs eram destinados somente ao público masculino até o ano de 1989. A situação começou a mudar nos anos 1980, e a pressão para o aceite de alunas teve início dentro das próprias instituições, por militares que buscavam oportunidades para suas filhas. Esse contexto culminou com a entrada das primeiras alunas no Sistema no ano de 1989 (CARRA, 2013).

O objetivo do presente estudo é descrever como se deu a transição das aulas de Educação Física do CMPA entre turmas separadas por sexo e por altura para turmas mistas no sexto e no sétimo anos do Ensino Fundamental. A opção por analisar estas turmas se deu porque eram as únicas na instituição organizadas considerando este modo de separação. O recorte temporal da pesquisa tem como marco inicial o ano de 1989 quando se deu a inserção de alunas na Instituição e finda em 2018, período no qual ocorreu a mudança.

Ao analisarmos essa transição, partimos do entendimento de que a Educação Física (EFI) é uma disciplina curricular que, ao trabalhar com os conteúdos da cultura corporal de movimento, investe no corpo como objeto de estudo e intervenção. De acordo com Silvana Goellner (2010) o corpo não é dado a priori, mas é uma construção que recebe marcas culturais, sociais, étnicas e que é mutável e mutante. Os corpos são gestualidades conformadas e transgressoras, que, em diferentes tempos e culturas, ritualizam simbologias e marcas cujas aparências expressam a diversidade humana. Um dos marcadores que atesta essa diversidade é o gênero, acolhido neste estudo também como uma categoria analítica, ou seja, uma "forma primária de dar significados às relações de poder" (SCOTT, 1995, p. 86), na medida em que é apenas no âmbito das relações sociais que se estabelecem os gêneros. Adotar este marcador identitário como categoria analítica não significa negar a biologia, mas recolocar o discurso no campo do social, pois é nele que se constroem as relações entre mulheres e homens, na história e nas condições de acesso aos recursos sociais (LOURO, 2001).

Considerando que o gênero não é inato, mas aprendido nas mais diferentes instâncias sociais, inclusive na escola, cabe destacar que a EFI se configura como um território no qual acontece essa aprendizagem, visto que se traduz como um espaço generificado (marcado pela diferença de gênero) e generificador (produtor da diferença de gênero). Helena Altmann e Eustáquia de Sousa (1999), ao analisarem as relações de gênero nas aulas mistas de Educação Física em uma escola pública da cidade de Campinas/SP, perceberam que os meninos ocupavam espaços mais amplos do que as meninas e se utilizavam da estratégia da transgressão para a conquista desses espaços. No entanto, elas utilizavam a estratégia que as autoras denominam de "não transgressão", ou seja, de cumprimento das regras da escola 
e de obediência, com a intenção de também conquistar aqueles espaços. Dessa maneira, elas desconstruíam uma possível relação de submissão. As autoras também identificaram que, acrescidos às questões de gênero, outros marcadores também possibilitaram a emergência de exclusões nos esportes como, por exemplo, habilidade, idade e força.

Ao analisar os discursos de docentes que justificam a separação de meninos e meninas como recurso didático-pedagógico necessário às aulas de Educação Física no contexto escolar, Priscila Dornelles (2007) ressalta que os argumentos geralmente circulam em torno da ideia de que os meninos são "naturalmente" mais fortes do que as meninas. Ou seja, reside no biológico do corpo a justificativa para a produção de representações generificadas, as quais, em grande medida, reafirmam práticas de privação da participação de meninas em algumas modalidades esportivas que exigem maior esforço físico e combatividade e, por conseguinte, o não incentivo para que meninos tomem parte em atividades que não sejam consideradas masculinas e masculinizadoras.

O CMPA, desde a entrada das primeiras alunas, promoveu as aulas de EFI dos primeiros anos atendidos (sexto e sétimo do Ensino Fundamental) separadas por sexo e por altura. A extinção desses critérios aconteceu somente no ano de 2018.

\section{FUNDAMENTAÇÃO TEÓRICO-METODOLÓGICA}

Com o intuito de entender como se deu o processo de extinção da separação das aulas de EFI no CMPA por sexo e altura, buscamos na História Oral a fundamentação teórico-metodológica desta pesquisa, entendida aqui como uma metodologia de produção de fontes mediante a realização de entrevistas. Para tanto, entrevistamos três professores e uma professora de EFI que atuam na instituição, entendendo que suas memórias colaboram para compreender a "presença do passado no presente imediato das pessoas" (MEIHY, 1998, p. 13), levando em conta a maneira como rememoram o acontecido. Ao recorrermos ao modo como significam sua prática docente, entendemos que estamos acessando experiências que são individuais e coletivas, pois, ainda que a memória seja guardada por um indivíduo tendo como referência suas experiências e vivências, ela está marcada pelo grupo social com o qual conviveu e se socializou, e essa sociabilidade se configura como um elemento essencial da formação de sua identidade, da percepção que tem de si mesmo e dos outros (ALBERTI, 1989; FERREIRA; AMADO, 1996).

Ao optar pelo trabalho com as memórias desses sujeitos, entendemos que suas lembranças não podem ser lidas como sendo a verdade sobre os acontecimentos, visto que entre o vivido e o narrado há uma mediação que é construída, também, pelas suas memórias (PESAVENTO, 2005). Memórias estas, muitas vezes, não registradas e que ao serem revividas permitem expandir os horizontes do nosso conhecimento sobre o mundo e estimulam o questionamento de nossas próprias hipóteses a respeito das experiências e dos pontos de vista de outras pessoas e culturas (PATHAI, 2010). 
O quadro de docente de EFI do CMPA é composto por onze professores (sete civis e quatro militares) e três professoras (duas civis e uma militar). O critério adotado para a escolha de quem entrevistar foi o fato de terem atuado nessa disciplina no período de transição de turmas exclusivamente destinadas a alunos do sexo masculino para turmas mistas. Cabe destacar que os entrevistados têm entre 52 e 76 anos de idade e entre 25 e 48 anos de atuação na instituição. Para preservar suas identidades optamos por utilizar nomes fictícios e por não explicitar as turmas com as quais trabalham.

As entrevistas foram registradas em um gravador digital seguindo a metodologia adotada pelo Projeto Garimpando Memórias ${ }^{1}$, desenvolvida junto ao Centro de Memória do Esporte (CEME) da Escola de Educação Física, Fisioterapia e Dança da Universidade Federal do Rio Grande do Sul (ESEFID), que contempla as etapas de transcrição, conferência de fidelidade, copidesque, assinatura do Termo de Consentimento Livre e Esclarecido e da Carta de Cessão de Direitos Autorais.

As narrativas oriundas das entrevistas foram colocadas em diálogo com documentos do SCMB e do CMPA, em especial aqueles que apresentam as normatizações da disciplina de Educação Física. O processo de análise do corpus empírico se deu embasado na proposição de Sandra Pesavento (2005) ao sugerir a imagem de um quebra-cabeça, cuja montagem pressupõe recolher os traços e registros do passado e realizar com eles um trabalho de construção, um "puzzle de peças, capazes de produzir sentido" (p. 64). Considerando essa representação, as informações oriundas das entrevistas e dos documentos foram confrontadas e analisadas entre si tendo como pano de fundo a inserção das alunas no CMPA e os desafios que essa presença demandou para o corpo docente da instituição.

\section{A INSERÇÃO DAS ALUNAS}

A origem do Sistema Colégio Militar do Brasil data do ano de 1889, com a criação do então Imperial Colégio Militar da Corte, atual Colégio Militar do Rio de Janeiro. O CMRJ era uma fonte privilegiada de produção de candidatos à carreira militar, pois possibilitava aos alunos uma boa preparação intelectual, por meio de um ensino rigoroso, bem como a iniciação à cultura militar, experienciada nas rotinas que envolviam marchas, manuseio de armamentos e utilização de fardamentos (CARRA, 2013).

O Colégio Militar de Porto Alegre foi o segundo a ser criado, em 1912, e até 1989 aceitou apenas alunos do sexo masculino. Inicialmente a disciplina de Educação Física destinava-se basicamente a atividades físicas e instruções militares, tendo como objetivos a criação de corpos sadios e a preparação para o ingresso em escolas militares. Até meados dos anos 1980, a vertente calistênica foi muito forte na instituição, o que demonstra o caráter preparatório para a carreira militar (CARRA, 2013).

Ao descrever as atividades desenvolvidas no Colégio, o professor Laurindo afirma:

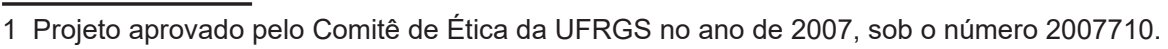


A gurizada toda, vinham pra cá com essa função, essa intenção: "Quero ir para a AMAN, quero ser militar". E como os professores eram basicamente militares, isso aí ajudava muito... A nossa Educação Física aqui era muito baseada na calistenia, à mão livre, com bastões, com halteres... Então era tudo mais militar... Não era só a calistenia que a Educação Física dava, tínhamos os treinos; cada professor, professor sargento no caso, tinha a sua equipe, atletismo, vôlei, basquete (Professor Laurindo, 2018, p. 5).

O professor Arthur, como foi aluno da instituição, em sua entrevista narrou algumas experiências que ele mesmo vivenciou:

\begin{abstract}
Quando eu era aluno, estamos falando final da década de 70, início de 80, a Educação Física não era com professores de Educação Física. Era com os monitores; os monitores são sargentos e era calistenia e corrida. Tinha uma coisa que era ginástica preparatória, que era uma ginástica feita para adultos, para os militares e eles faziam isso pra gente com o monitor... No Ensino Médio eu era atleta, daí eu já não fazia mais Educação Física, eu só treinava a minha modalidade que era o Pentatlo (Professor Arthur, 2018, p. 5).
\end{abstract}

No momento que se deu a entrada das alunas no Colégio Militar, as aulas de EFI não só eram separadas por sexo como o conteúdo também era diferenciado (CARRA, 2013). Os alunos realizavam atividades físicas mais intensas, voltadas à preparação de um corpo forte e ágil para a carreira militar, caso assim escolhessem. Essa intencionalidade não figurava para as alunas, já que não Ihes era permitido seguir a mesma carreira. Para elas eram ministradas atividades físicas consideradas condizentes com o ideal para uma educação feminina, tais como ginásticas variadas e de intensidade fraca ou o voleibol (CARRA, 2013). Vale ressaltar que foi apenas em 1984 que o CMPA realizou o primeiro concurso de admissão de professores civis para a disciplina de Educação Física, o que favoreceu o oferecimento de uma variedade maior de atividades, havendo inclusive a inserção de aulas teóricas.

Ainda assim a separação por sexo se fez presente mesmo que não houvesse um documento que determinasse esse proceder. Segundo os professores e a professora entrevistada, os critérios para a organização das turmas eram exclusivos dos docentes. O professor Arthur, ao responder se as turmas eram separadas quando as alunas ingressaram no CMPA, recorre à história da instituição:

\footnotetext{
Sim, sempre. Mas na verdade não: eu trabalhava muito com atletismo e sempre foi misto, tinha uma turma de ginástica, era uma turma do pessoal que não gostava de esportes com bola. Essa turma também era mista, algumas turmas de basquete eram mistas, mas em geral eram separadas. Por exemplo, futebol nunca era misto; handebol houve algumas turmas de meninas, mas na maioria eram turmas só de guris. [...] Teve um sargento também, que dava ginástica de academia e na época ele chegou a montar grupos de ginástica aeróbica e era basicamente só meninas. Então tinha diferença nisso, no que era proposto (Professor Arthur, 2018, p. 5).
}

O professor também menciona que não havia proibições formais quanto à participação de alunos e alunas em nenhuma modalidade esportiva. No entanto, no momento da escolha pela modalidade a praticar, os alunos e as alunas se deparavam com práticas e discursos que reiteravam as diferenças biológicas como o critério que demarcava as escolhas, em grande medida, generificadas visto que já estavam impregnadas por um "aprendizado da separação entre os sexos" (AUAD, 2006, p. 59). 
As práticas corporais eram feitas em rodízio, com um número determinado de aulas para cada modalidade, cuja variação dependia da disponibilidade de salas, quadras, professores e por outros fatores inerentes ao cotidiano escolar. O caráter generificado estava presente inclusive em documentos que regiam a prática pedagógica. Ao analisar o Planos de Área de Estudo, de 1998, identificamos que a dança constava como um conteúdo possível de ser trabalhado na aula de EFI. No entanto, um adendo demarcava para quem preferencialmente essa prática era direcionada: "O Colégio Militar que optar pela modalidade esportiva Dança poderá repetir a modalidade de maior aceitação para os meninos que assim o desejarem" (BRASIL, 1998, p. 14). Interessa registrar que para as alunas essa possibilidade não existia: aquelas que não se interessassem pela dança não tinham a oportunidade de optar por alguma outra modalidade pressupondo, assim, que a dança era relacionada a elas e não a eles.

No que se refere às rotinas militares do CMPA, o professor Laurindo afirma que as formaturas ${ }^{2}$ foram ficando mais leves com o tempo, tendo a entrada das alunas como marco inicial da flexibilização. Em sua entrevista, menciona que o Colégio adaptou as rotinas de ordem unida para que as meninas pudessem aguentar o esforço físico exigido nessa rotina e, também para minimizar o protagonismo dos alunos que, na maioria das vezes, se colocavam mais à frente nos posicionamentos e filas. Essa adaptação, no entanto, já circulava na escola. Segundo Patrícia Carra (2013), as rotinas já vinham sendo flexibilizadas antes da entrada delas sob a alegação de que um aluno não era o mesmo que um soldado e que, portanto, deveria ser tratado de maneira mais amena. A entrada de professores civis já era um indicativo da flexibilização das exigências físicas para atividades de cunho militar. A preocupação com o bem-estar dos alunos durante as rotinas físicas, considerando que eram todos adolescentes e com o corpo ainda em formação, se fazia presente nesse contexto e se acentuou com a entrada das meninas. Nas palavras do professor Laurindo:

O nível de exigência era muito maior, por exemplo, as formaturas da gurizada, que eram aqueles que pretendiam ir pra AMAN, mais fortinhos, então eles ficavam em uma formatura 10, 15 minutos se fosse necessário e eles aguentavam, não tinha problema, tinha internato inclusive, então a gurizada era forte. Com o advento das meninas, [...] passou-se a ter aquela preocupação, aquele cuidado de não deixar muito tempo pra não dar malestar, desmaio, aquele negócio todo (Professor Laurindo, 2018, p. 8).

Em sua entrevista, o professor também discorre sobre as diferenças de se trabalhar com meninas e com meninos. Segundo sua opinião, eles são mais fortes e aguentam críticas mais pesadas, enquanto que, com elas, é preciso ter cuidado e falar com jeito para evitar a desestabilização emocional, o que prejudicaria o desempenho esportivo. Tal argumento está assentado em um modelo binário que pressupõe a existência de dois sexos distintos, os quais originam verdades sobre ser homem e ser mulher, fixando representações de masculinidade e feminilidade ${ }^{3}$.

\footnotetext{
2 Consiste em um grupo de pessoas (na escola são turmas, mas em quartéis são tropas ou "grupamentos") que é organizado em colunas por meio de comandos militares. É um momento de reunião comumente utilizado para dar avisos relativos ao cotidiano escolar, durando poucos minutos, ou então para solenidades formais, com duração mais longa, podendo ser de grande exigência física.

3 Thomas Laqueur (2001), no livro Inventando o sexo: corpo e gênero dos gregos a Freud, vai tornar evidente como em diferentes momentos históricos o corpo biológico foi tomado como justificador de diferenciações políticas, culturais e sociais entre os sexos.
} 
A narrativa desse professor permite identificar que muitas das adaptações feitas pelo CMPA foram pautadas pela diferença biológica entre os sexos, ou seja, na ideia de que mulheres e homens têm características distintas e inatas que projetam traços de caráter e de comportamento, funções sociais, espaços de pertencimento e possibilidades de socialização para eles e para elas, inclusive no esporte (GOELLNER, 2013).

A diferenciação entre os sexos nas aulas de EFI se deu também no uso das roupas. O primeiro uniforme esportivo direcionado para as alunas era constituído por uma camiseta regata utilizada sobre um top, conjunto que era acompanhado por um short relativamente largo. Seu uso provocou reações, e a referência de que partes do corpo das meninas ficavam expostas começaram a circular no CMPA. Criou-se, então, uma bermuda de lycra para ser obrigatoriamente usada por baixo do short largo com o intuito proteger o corpo feminino de desconfortos, olhares e eventuais constrangimentos (CARRA, 2013).

Cabe registrar que o conjunto utilizado pelas alunas se mantém desde o início dos anos de 1990, apesar de os professores referirem que já foram feitas várias tentativas de modificá-lo apresentando "relatos técnicos de que o uniforme não era adequado à prática de atividade física" (Professor Arthur, 2018, p. 09). No entanto, a instituição mantém o argumento inicial para a sua manutenção: preservar o corpo feminino. Ou seja, não se discute a necessidade de educar o olhar masculino, mas a de encobrir o corpo feminino. Segundo a professora Ana:

[...] as pessoas que estavam olhando as meninas, em vez de tapar as meninas, deveriam propor algum tipo de educação no olhar porque essa bermuda que as meninas usavam era normal, qualquer pessoa usa. Não era uma vestimenta ousada, era uma vestimenta de esporte que todo mundo usa (Professora Ana, 2018, p. 6).

Se pensarmos que as roupas compõem estratégias de educação do corpo, a diferenciação sexual do uso do uniforme esportivo produz um repertório gestual distinto, no qual aos alunos é permitida a construção de um repertório motor mais diversificado. Segundo Carmen Soares (2011), as roupas "revelam ligações com poderes e saberes, sugerindo hierarquia sexual dos papéis familiares, sublinhando a força das crenças, seja pelos detalhes que portam, seja mesmo pelo que oferecem como conjunto coeso" (p. 130).

Helena Altmann (2015), ao analisar as propagandas de calçados infantis, lança luz à grande diferença no enfoque dado aos calçados para meninas e para meninos. Para elas, valoriza-se a beleza, a estética e o desconforto. Para eles, o conforto, a destreza e o movimento. Poucas são as imagens que vinculam meninas ao movimento e, menos ainda, a uma modalidade esportiva de modo mais específico. As roupas, assim como outros dispositivos de educação do corpo, ensinam modos de ser e de se comportar. Ao limitarem movimentos sob o argumento de que as meninas precisam proteger os seus corpos, se produz uma timidez corporal pautada pelo comedimento dos gestos. Nesse sentido, o espaço escolar tende a ser dominado pelos alunos, reproduzindo as relações de gênero que foram se tornando normais na sociedade e sendo ensinadas às crianças (LOURO, 2001). 
Para além da divisão das aulas de EFI por sexo, uma particularidade mostrase relevante quando analisamos a educação dos corpos no CMPA. Até o ano de 2017, as turmas de sexto e sétimo anos ${ }^{4}$ eram divididas também por altura, sendo a única instituição que integra o Sistema Colégio Militar do Brasil a adotar tal prática. A designação utilizada pelos docentes era turmas femininas de baixa estatura (F1) e de alta estatura (F2), o mesmo ocorrendo com as turmas masculinas de baixa estatura (M1) e de alta estatura (M2).

Segundo as narrativas dos professores e da professora entrevistados/a, esta determinação se deu por conveniência do próprio corpo docente que lecionava no CMPA no início da década de 1990, visto que, em sua maioria, atuavam em esportes de competição e tinham como objetivo o ensino da técnica esportiva. Quando questionados/a sobre a existência de documentos que regulamentavam essa escolha, afirmaram que não havia ou que os desconhecem:

\begin{abstract}
Como todos nós vínhamos do esporte de competição, a gente dava o enfoque nas aulas, mesmo que a gente fosse inclusivo, e a gente era inclusivo, a gente tinha essa preocupação da participação e tudo isso, mas a nossa aula, a nossa prática era performática, era mais ligada à performance, à execução do movimento. Eu não me lembro de onde veio isso, se nós decidimos, se já estava decidido e a gente não criticou e seguiu fazendo porque era mais cômodo. A origem disso eu não sei, mas era isso que a gente fazia, aquelas coisas que a gente nunca pensa, né? A gente faz e repete (Professor Arthur, 2018, p. 8).
\end{abstract}

A escassa normatização da disciplina nos marcos documentais da instituição permitiu que sua execução fosse orientada por quem a conduz. O critério da separação por sexo e por altura buscava a composição de turmas homogêneas, consideradas mais convenientes ao ensino das modalidades esportivas que, segundo recomendado no Plano de Sequências Didáticas "deverão ser ministradas na forma de rodízio" (BRASIL, 2011, p. 4). Em sua entrevista, a professora Ana justifica que esse modo de separação foi a solução adotada porque "facilitava e permitia trabalhar melhor com as crianças que poderiam ser atletas daquela modalidade" (Professora Ana, 2018, p. 1), mesmo que em nenhum documento do Sistema Colégio Militar do Brasil apareça a formação de atletas como uma das metas das instituições que o integram.

Um fator que legitima esse tipo de separação é a hegemonia do esporte como o principal conteúdo das aulas de Educação Física e sua organização em torno da perspectiva do rendimento (JESUS; DEVIDE, 2006). Em função dessa perspectiva, os discursos que sustentam uma suposta homogeneidade, tanto no masculino quanto no feminino, encontram respaldo em discursos biologistas que apagam as singularidades e desconsideram outros marcadores identitários como classe, raça/ etnia, orientação sexual e geração. Seguindo esse raciocínio, a força seria atributo inato ao corpo masculino, como essência de sua biologia; os meninos seriam naturalmente fortes e mais propensos à violência e as meninas, frágeis e apáticas (DORNELLES, 2007; GOELLNER et al. 2012).

\footnotetext{
4 Segundo os documentos que regem o ensino da Educação Física no CMPA, no oitavo ano os/as discentes passam a ter autonomia para decidir qual esporte querem praticar dentre as opções oferecidas para o seu ano, que podem variar segundo disponibilidade de espaços e de professores. As turmas podem ser mistas ou não.
} 
Essas representações permitem identificar o quanto os docentes do CMPA, ao sustentarem o argumento da separação por sexo e altura, tomaram a lógica binária como aquela que informa sobre as diferenças entre os sexos, e a reproduziram ao operar com o esporte. Ao assumirem essa representação, produziram práticas esportivas generificadas (marcadas pela diferença de gênero) e generificadoras (produtoras da diferença de gênero), tomando o esporte como protagonista da definição do que se entende e espera de um homem e de uma mulher. Segundo Marco Ferreti e Jorge Knijnik (2007):

[...] o esporte é uma das instituições sociais em que, inclusive por sua corporeidade, se manifestam as ideologias sobre o masculino e o feminino que estão em permanente tensão [...] favorecendo desta forma o emprego das diferenças biológicas para justificar como natural a construção social dos gêneros (p. 58).

A lógica binária, ao colocar masculino e feminino em oposição, impossibilita a percepção das pluralidades e das diversidades ocultando, as múltiplas identificações existentes entre os lados opostos (SCOTT, 2005). Com isso, "[...] cada lado da oposição é apresentado e representado como um fenômeno unitário. Assume que tudo em cada categoria (mulher/homem) é a mesma coisa (é igual); portanto, se suprimem as diferenças dentro de cada categoria" (MARIANO, 2005, p. 487).

Interessa registrar que no Plano de Sequências Didáticas do CMPA, direcionado tanto ao sexto quanto ao sétimo ano do Ensino Fundamental, não existem recomendações para a separação das turmas de EFI nem por sexo e muito menos por altura. O que está explícito no documento vai na direção contrária, como podemos verificar na descrição da competência um ${ }^{5}(\mathrm{C} 1)$ e de sua respectiva habilidade quatro $(\mathrm{H} 4)$ :

C1 - Participação em atividades de natureza relacional, reconhecendo e respeitando suas características físicas e de desenvolvimento motor, bem como a de seus colegas, sem discriminar por características pessoais, físicas, sexuais ou sociais.

H4 - Reconhecer e valorizar atitudes não discriminatórias quanto à habilidade, sexo ou outras, como conduta eficiente para inclusão de todos nas práticas da cultura corporal de movimento (BRASIL, 2011, p. 6).

Acrescenta-se a isso a determinação que consta em um dos documentos oficiais sobre a organização das turmas de aulas nos $\mathrm{CMs}$, no qual é reiterado que se criem turmas heterogêneas no que diz respeito a sexo, rendimento escolar e origem (concursado/filho de militar). Ao versar sobre a constituição das turmas, apesar de não especificar à qual disciplina se refere, recomenda: "Cada turma de aula deverá ser constituída de alunos e alunas, não devendo o percentual de determinado sexo ser superior ao outro em mais de $20 \%$ " (BRASIL, 2016, p. 13).

Diante de argumentos e documentos como os supracitados, a separação por sexo e por altura passou a ser questionada por alguns integrantes do corpo docente do próprio CMPA. Um marco importante para que a emergência dessa discussão fosse travada, de fato, foi o evento trienal ${ }^{6}$ destinado a fazer a revisão curricular

5 O total de competências para o Ensino Fundamental é sete, que se desmembram em 22 habilidades. Para o Ensino Médio, são 16 competências e 27 habilidades.

6 Evento realizado na cidade de Itaipava/RJ em setembro do ano de 2017, com a presença de um/a representante de cada disciplina da área de Linguagens, Códigos e suas Tecnologias dos treze Colégios Militares do Brasil. 
da área de Linguagens, Códigos e suas Tecnologias de todo o Sistema. Em meio a debates e exposição do contexto de cada CM no que concerne à disciplina de Educação Física, ficou evidente que o CMPA era um dos únicos a ainda manter a separação por sexo e, para surpresa dos colegas presentes, também por altura.

Diante disso, os critérios de constituição das turmas passaram a ser questionados por integrantes do corpo docente do próprio CMPA. O principal debate sobre o assunto aconteceu durante uma reunião realizada na instituição em outubro do ano de 2017, logo após o término evento nacional que pautou a revisão curricular dos CMs. Nessa reunião, os/as professores/as favoráveis à alteração para turmas mistas fizeram uma exposição sobre o tema, fundamentados na experiência dos outros CMs e na documentação oficial do SCMB. Apesar de haver opiniões contrárias por parte de docentes que demonstravam receio em mudar o que já vinha "funcionando" há muito tempo, houve o entendimento de que a separação das turmas por sexo e por altura estava em desacordo com os documentos do próprio Sistema. Ainda assim a decisão que efetivou a alteração aconteceu apenas no início do ano de 2018, quando se deu a montagem das turmas para trabalhar o novo ano letivo. Esse processo foi protagonizado por docentes favoráveis à alteração que, ao organizarem as turmas dos sexto e sétimo anos fizeram uso de estratégias que contemplaram a presença igualitária de alunos e alunas, descartando de vez a organização por sexo e por altura.

Essa decisão foi apresentada em reunião do corpo docente da área da EFI, a qual foi acatada. Interessa destacar que não houve nenhuma formalização dessa alteração junto à direção do Colégio já que, segundo o entendimento da Supervisão Escolar, a Educação Física sempre foi "pouco normatizada" quanto aos detalhes de sua execução, ou seja, as determinações que a regiam eram feitas mais em um sentido geral do que específico.

As falas dos professores Arthur e Aristeu explicitam a importância da reflexão sobre as mudanças:

Eu acho que não tem como ser [turma] separada né? Mas nós estamos vivendo uma situação nova... A gente tem que pensar, a gente tem que refletir sobre algumas práticas [...] é difícil, é uma mudança de paradigma na cabeça também, afinal de contas são vinte e tantos anos fazendo do mesmo jeito (Professor Arthur, 2018, p. 7).

Pode ser um desafio para o professor, trabalhar com turmas de gêneros diferentes, mas em termos de dinâmica de aula eu penso que está sendo bem agradável, estou gostando, acho que isso sempre me faz pensar um pouco mais naquilo que eu tenho que fazer, na forma que eu tenho que conduzir a aula (Professor Aristeu, 2018, p. 04).

Isso de modo algum implica afirmar a ausência de resistências, adaptações e negociações. Os/a professores/a foram unânimes em dizer que a interação com os diferentes é importante e que o trabalho em turmas mistas é muito rico para promover o respeito e a aceitação do outro. No entanto, consideraram que é desafiante trabalhar de forma conjunta porque exige que se criem novas estratégias e possibilidades de ensino, quebrando, de certo modo, um paradigma já arraigado na instituição e no seu fazer pedagógico. Vejamos algumas de suas falas: 
[...] é difícil, é uma mudança de paradigma na cabeça também, afinal de contas são vinte e tantos anos fazendo do mesmo jeito (Professor Arthur, 2018, p. 8).

Eu acredito assim, a aula separada é mais fácil de dar e às vezes eles gostam mais. Eu acho que não precisaria ser de um jeito só porque pode ter momentos que tu queira ficar com aqueles teus pares, vamos dizer, nesse quesito de sexo, pra fazer alguma atividade, em outros momentos tu pode fazer o trabalho misto [...] (Professora Ana, 208, p. 2).

Olha, tem os prós e os contras... Os prós é que, como o trabalho é o mesmo pra todos, o que está formando, ensinando, aquele negócio todo, é o mesmo, é a mesma coisa, com o mesmo grau de exigência, não teria problema ser masculino e feminino juntos. O contra é, se na hora de separar, por exemplo, botar guris contra gurias? A vantagem é dos guris sempre... A parte física, aquele negócio todo... Não tem dúvida né (Professor Laurindo, 2018, p. 10).

Apesar de acatarem as decisões das instituições militares de acabar com a separação das turmas por sexo e altura, os/a professores/a mencionam algumas preocupações em especial por entenderem que meninos e meninas apresentam habilidades e performances diferenciadas, o que poderia, por vezes, dificultar tanto o trabalho do docente como o aprendizado dos/as alunos/as. Tais narrativas indicam que, findo o período no qual as aulas de Educação Física eram organizadas tendo como critérios básicos o sexo e a altura dos/as alunos/as, o corpo docente do CMPA teve que se adaptar às novas orientações e, de algum modo, refletir sobre as questões de gênero.

\section{CONSIDERAÇÕES FINAIS}

Em que pese o Exército Brasileiro, instituição que rege o ensino no CMPA, ser hoje uma instituição mista desde a sua base até a principal escola de formação ${ }^{\text {, }}$ a Educação Física do Colégio Militar de Porto Alegre ainda tem um longo caminho a trilhar no que diz respeito às questões coeducativas. Embora o CMPA seja uma escola mista há 30 anos, a disciplina de Educação Física manteve as turmas de sexto e de sétimo anos do Ensino Fundamental separadas por sexo e por altura até o ano de 2018, enquanto todas as outras disciplinas curriculares já eram mistas.

A proposição de turmas mistas foi um avanço na instituição, mas é importante registrar que, por si só, não garante um espaço coeducativo. Ou seja, não garante que as oportunidades e atividades sejam equânimes para alunos e para alunas, tampouco garante o tratamento igualitário e a problematização sobre as desigualdades de gênero existentes no âmbito da aula, da escola e da sociedade em geral.

Em entrevista concedida à plataforma UOL, no dia 23 de dezembro de 2018, o General Lancia, Diretor de Educação Preparatória e Assistencial e comandante do Sistema Colégio Militar do Brasil, à época, fez a seguinte afirmação:

O projeto pedagógico atual diz que o nosso sistema é baseado nos valores
e tradições do Exército, respeito aos valores sociais, patrióticos e familiares
e prepara jovens para serem cidadãos cônscios de seus deveres e que não
sejam simplesmente repetidores daquilo que se aprendeu na sala de aula.

7 A Academia Militar das Agulhas Negras, escola que forma o/a bacharel em Ciências Militares, permitiu a entrada das primeiras alunas/cadetes no ano de 2018. 
Pensamento crítico: é o que mais a gente faz, isto é, estimular o nosso aluno a ter uma visão além do que a gente passa ali de conhecimento, porque, senão, seria um robô. Só repetiria o que é ensinado. Muito pelo contrário, nossos alunos pensam fora da caixa ${ }^{8}$.

Considerando esta declaração, entendemos que as aulas mistas são fundamentais para promover modos de "pensar fora da caixa" ao possibilitarem, por exemplo, desconstruir práticas e representações que, fundamentadas pelo discurso biológico, promovem desigualdades entre alunos e alunas no contexto da disciplina Educação Física. Para que isso aconteça, urge discutir e traçar estratégias voltadas para a superação de um modo de operar instituído há muito tempo, o que inevitavelmente vai exigir do corpo docente da instituição vontade política e pedagógica. Desafio necessário e imprescindível para que os/as alunos/as da instituição possam vivenciar situações equânimes do ponto de vista da cultura corporal de movimento, desenvolver o pensamento crítico e, de fato, pensar fora da caixa.

\section{REFERÊNCIAS}

ALBERTI, Verena. Manual de História Oral. Rio de Janeiro: Editora FGV, 1989.

ALTMANN, Helena. Educação física escolar: relações em jogo. São Paulo: Cortez, 2015 (Coleção Educação \& Saúde).

ALTMANN, Helena; SOUSA, Eustáquia. Meninos e meninas: Expectativas corporais e implicações na educação física escolar. Cadernos Cedes, ano XIX, n. 48, p. 52-68, ago. 1999.

AUAD, Daniela. A coeducação como política pública: a manutenção da escola mista com o advento da igualdade de gênero. Caderno Espaço Feminino, v. 16, n. 19, jul./dez. 2006.

BRASIL. Ministério da Defesa. Exército Brasileiro. Normas de Planejamento e Gestão Escolar. Brasília, DF, 2016.

BRASIL. Ministério da Defesa. Exército Brasileiro. Plano de Área de Estudo - Ensino Fundamental. Disciplina: Educação Física Escolar. Aprovado pelo Boletim Interno da Diretoria de Ensino Preparatório e Assistencial n. 119, de 23 de outubro de 1998. Brasília,DF, 1998.

BRASIL. Ministério da Defesa. Exército Brasileiro. Plano de Sequências Didáticas - $6^{\circ}$ ano. Brasília,DF, 2011.

CARRA, Patrícia Augusto. Baleiros e baleiras no velho casarão: coeducação ou escola mista no Colégio Militar de Porto Alegre? (RS - 1989 a 2013). 2013. 298 f. Tese (Doutorado em Educação) - Pontifícia Universidade Católica do Rio Grande do Sul, Porto Alegre, 2013.

DORNELLES, Priscila Gomes. Distintos destinos? A separação entre meninos e meninas na educação física escolar na perspectiva de gênero. 2007, 156f. Dissertação (Mestrado em Educação). Faculdade de Educação. Universidade Federal do Rio Grande do Sul, Porto Alegre, 2007.

8 Disponível em: https://educacao.uol.com.br/noticias/2018/12/23/colegios-militares-exercito-governo-jair-bolsonarodisciplina.htm. Acesso em: 18 nov. 2018. 
FERRETTI, Marco; KNIJNIK, Jorge. Mulheres podem praticar lutas? Um estudo sobre as representações sociais de lutadoras universitárias. Movimento, v. 13, n. 1, p. 57-80, dez. 2007. Disponível em: https://seer.ufrgs.br/Movimento/article/view/2925. Acesso em: 08 jul. 2019.

GOELLNER, Silvana. A educação dos corpos, dos gêneros e das sexualidades e o reconhecimento da diversidade. Cadernos de Formação RBCE, v.1, n. 2, p. 71-83, mar. 2010.

GOELLNER, Silvana et al. Sobre os feminismos, o esporte e o potencial pedagógico dessa relação. Labrys, estudos feministas, v. 22, n.1, p. 12-22, jul./dez. 2012.

GOELLNER, Silvana. A contribuição dos estudos de gênero e feministas para o campo acadêmico-profissional da Educação Física. In: DORNELLES, P. G.; WENETZ, I.; SCHWENGBER, M. S. V. Educação Física e Gênero: desafios educacionais. ljuí: UNIJUÍ, 2013. p. 23-43.

JESUS, Mauro; DEVIDE, Fabiano. Educação física escolar, coeducação e gênero: mapeando representações de discentes. Movimento, v. 12, n. 3, p. 123-140, set./dez. 2006.

LAQUEUR, Thomas. Inventando o sexo: corpo e gênero dos gregos a Freud. Rio de Janeiro: Relume, 2001.

LOURO, Guacira. Corpo, escola e identidade. Educação e realidade, v. 25, n. 2, p. 59-76 jul./dez. 2001.

MARIANO, Silvana A. O sujeito do feminismo e o pós-estruturalismo. Revista Estudos Feministas, v. 13, n. 3, p. 483-505, set./dez. 2005.

MEIHY, José Carlos Sebe Bom. Manual de História Oral. 2. ed. São Paulo: Loyola, 1998.

PATHAI, Daphne. História Oral, feminismo e política. São Paulo: Letra eVoz, 2010.

PESAVENTO, Sandra Jatahy. História \& história cultural. Belo Horizonte: Autêntica, 2005.

SCOTT, Joan. Gênero: uma categoria útil de análise histórica. Educação \& Realidade, v. 20, n. 2, p. 71-99. jul./ dez. 1995.

SCOTT, Joan. O enigma da igualdade. Revista Estudos Feministas, v. 13, n. 1, p. 11-30, 2005.

SOARES, Carmem Lúcia. As roupas nas práticas corporais e esportivas. Campinas: Ed. Autores Associados, 2011. 